\title{
Identification and management of critical erosion watersheds for improving reservoir life using hydrological modeling
}

\author{
Sanjeet Kumar ${ }^{1} \cdot$ Narendra Singh Raghuwanshi $^{1} \cdot$ Ashok Mishra $^{1}$
}

Received: 9 March 2015/ Accepted: 21 April 2015/Published online: 8 May 2015

(C) Springer International Publishing 2015

\begin{abstract}
Sustainable management of water resources requires identification and management of critical erosion areas for reducing the reservoir sedimentation. A processbased distributed model SWAT (Soil and Water Assessment Tool) was used to identify critical erosion watersheds in Damodar catchment and tested soil and water management strategy to reduce sediment transport to reservoirs for improving their useful life. The model was calibrated and validated using measured runoff and sediment yield from two watersheds and two reservoir inflows. The validated model was also tested for its appropriateness by comparing the identified critical erosion area of the catchment with the erosion map prepared by Soil Conservation Department (SCD), Damodar Valley Corporation (DVC). The results show that the critical erosion area identified using modeling results matched spatially well with the DVC manually prepared area. Further, the validated model has been used to simulate the sedimentation in the reservoirs. The simulated sedimentation rate is 1.12 and $3.65 \mathrm{Mm}^{3} /$ year, respectively, for Konar and Panchet reservoirs for the studied period (1997-2001), which is reduced to 0.98 and $1.80 \mathrm{Mm}^{3} /$ year, respectively, when the critical watersheds are treated with conservation measures. As a result of model identified and implemented management strategy, Konar and Panchet reservoirs will have an additional useful
\end{abstract}

Sanjeet Kumar

sanjeetiitkgp@gmail.com

Narendra Singh Raghuwanshi

nsr@agfe.iitkgp.ernet.in

Ashok Mishra

amishra@agfe.iitkgp.ernet.in

1 Department of Agricultural and Food Engineering, Indian Institute of Technology, Kharagpur 721302, India life of 8 and 85 years, respectively. Results show a successful incorporation of distributed hydrological modeling for identifying critical watersheds, developing effective management strategy for controlling soil erosion, reducing reservoir sedimentation and improving their useful life.

Keywords Critical erosion areas - Reservoir sedimentation $\cdot$ SWAT $\cdot$ Sediment management $\cdot$ Reservoir life

\section{Introduction}

Multipurpose reservoirs are constructed across the rivers with objectives like flood control, irrigation, hydropower generation, and water supply for industrial and domestic uses (Morris and Fan 1998). Sedimentation is a major problem in reservoirs, which reduces the potential water storage capacity (McCully 1996; Cantelli et al. 2004) and leads to decreased water availability, increased evaporation losses, backwater flooding, and damage to hydropower stations (Morris and Fan 1998). These problems result in loss of benefits from the multipurpose reservoir projects constructed at huge costs.

Runoff and soil erosion from the catchment result from the complex interrelationships among climate, drainage area, land use and land cover (LULC), and human activities (Fan et al. 2004; Walling 2006; Roosmalen et al. 2009). Soil erosion process neither takes place from every part of the catchment nor is equally distributed because of varying differences of natural and man-made conditions. However, there are some critical areas in the catchment responsible for the high soil erosion (Tripathi et al. 2003; Srinivasan et al. 2005; Pandey et al. 2007; Xu et al. 2009). Effective 
control of soil loss requires implementation of effective management practices in critical erosion areas which can be done only if those areas are identified properly (Tripathi et al. 2003; Bracmort et al. 2006; Donnell et al. 2008; Tian et al. 2009). During the last two decades, there has been a dramatic increase in use of physically based distributed models, remote sensing technique and geographical information system to simulate complex hydrological processes of the watersheds. SWAT model (Arnold et al. 1998) has been used successfully for simulating runoff, sediment yield and water quality and is established as a useful tool for simulating hydrological processes in the catchment/ watershed. In recent studies, researchers have applied the SWAT model both for identifying the critical erosion areas (Tripathi et al. 2003; Behera and Panda 2006; Xu et al. 2009) and for developing the best management practices (Mapfumo et al. 2004; Tripathi et al. 2005; Tuppad et al. 2010; Zhang et al. 2010; Zhang and Zhang 2011; Smith et al. 2013) for these critical erosion areas in the watershed.

There are several methods which have been used in past to determine the amount of sediment in reservoirs, such as hydrography (Furnans and Austin 2008), mathematical and computer models (Jothiprakash and Garg 2009; Mueller et al. 2010; Wu et al. 2012), hydrometry (Heidarnejad et al. 2006), bathymetric survey (Haregeweyn et al. 2012) and remote sensing (Goel et al. 2002). But due to the differences in technique and environmental conditions; a comprehensive, precise, and economic method cannot be recommended. It has been found from the literature review that during estimation of reservoir sedimentation rate, researchers mostly neglected the properties of the drainage catchment, the main source of the sediment to the reservoir. It has been documented by many researchers around the world that LULC change, climate condition and human activities in the drainage catchment of a reservoir are largely responsible for increased reservoir sedimentation (Dearing and Jones 2003; Rose et al. 2011; Schiefer et al. 2013). To improve technical, economical and environmental sustainability of reservoirs, the sediment source, possible changes in the drainage catchment and climate conditions must be studied carefully when considering the useful life of the reservoir. However, the use of hydrological modeling for reservoir sedimentation, control and management of sedimentation, and formulating the strategy to improve their life, has rarely been done so far except in a recent few studies (Sardar et al. 2013; Hunink et al. 2013). Keeping this gap in mind of hydrological model application in managing reservoir sedimentation, SWAT model was used first for identification of critical erosion area and then for developing a management plan to reduce the reservoir sedimentation.

The study area is Damodar River catchment, located in Jharkhand state of India. The river has a high significance in the development of water resources, agriculture, mining, fishing and livestock production in the area. Existing reservoirs in the catchment are seriously affected by sedimentation due to high soil erosion rate in the catchment. High topographical variation, mining activities, agricultural activities and temporal rainfall variation within the catchment characterize the large quantity of runoff associated with high amount of sediment. Damodar catchment is dominated by industrial and mining activities. Due to open cast and illegal mining, mining washery industries increased the sediment inflow to the reservoirs located in the Damodar catchment. All these aspects have raised a serious concern about the reservoirs operation and other activities. To date no study is reported considering whole catchment and reservoirs; there are a few studies only on watersheds (Tripathi et al. 2003; Mishra et al. 2007; Pandey et al. 2007). SWAT model was used first for identification of critical erosion area and then for developing a management plan to reduce the reservoir sedimentation. The present study has been undertaken with the following objectives: (1) parameterization of SWAT model for two watersheds within the catchment to simulate the runoff and sediment yield and then up-scaling of validated model to Damodar catchment for the identification of critical erosion watersheds; (2) estimation of reservoir sedimentation based on sedimentation rate obtained during study period and (3) implementation of an effective management plan to critical watersheds and simulation of their effects on the sedimentation and life of the reservoirs.

\section{Materials and methods}

\section{Study area and data description}

Upper Damodar catchment, a part of the lower Ganges River, is located in the upper reaches of the Damodar River basin in the Jharkhand state of India (Fig. 1). The area lies between $23^{\circ} 34^{\prime}$ to $24^{\circ} 91^{\prime}$ North latitude and $84^{\circ} 42^{\prime}$ to $86^{\circ} 46^{\prime}$ East longitudes with an elevation variation between 122 and $1340 \mathrm{~m}$ above mean sea level. The catchment area is about $10,878 \mathrm{~km}^{2}$ and the length of the main stream is about $250 \mathrm{~km}$. There are two reservoirs (Konar and Panchet) located on the river and both are used for hydropower generation, irrigation, flood control, etc. The catchment is dominated by sub-tropical climate. Daily mean relative humidity varies from 40 to $95 \%$ with alternating dry and wet periods. The daily temperature ranges from a minimum of $3{ }^{\circ} \mathrm{C}$ to a maximum of $44{ }^{\circ} \mathrm{C}$ with average annual rainfall of $1250 \mathrm{~mm}$, more than $80 \%$ of which occurs during July to September, the monsoon season. The vegetation of the study area comprises mixed forest, mainly 


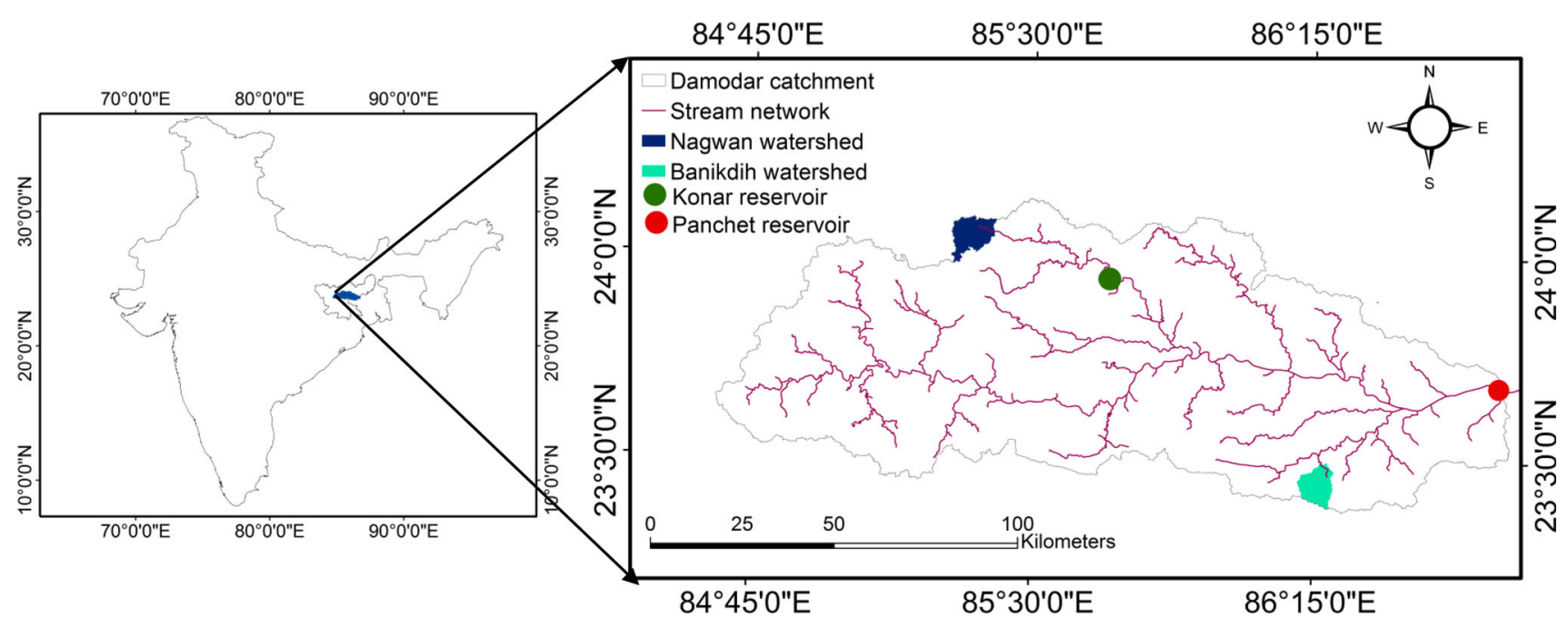

Fig. 1 Location map of Damodar catchment showing Nagwan and Banikdih watersheds and Konar and Panchet reservoirs

deciduous and tropical moist forest, and rainfed agricultural areas. Major crops grown are rice, groundnut, maize in monsoon season and wheat, mustard and some vegetables in winter (DVC 2007).

Daily rainfall, minimum and maximum air temperature for 1991-2001, monthly runoff and sediment yield data for 1997-2001 during monsoon season were collected for Nagwan and Banikdih watersheds from the Soil Conservation Department (SCD), Damodar Valley Corporation (DVC), Hazaribagh, India. More than $80 \%$ of the annual rainfall was confined to the monsoon period (JuneSeptember), resulting in high amounts of runoff and sediment yield from the catchment. Gauging of runoff and sediment yield is done only in monsoon season, as there is no flow or less flow in other months of the year. Daily inflow and outflow data for 1991-2001 period, reservoir sedimentation and capacity survey reports for Konar (CWC 1998) and Panchet (CWC 1996) reservoirs were obtained from the Reservoir Operation Department, DVC, Maithon, Jharkhand, India. Konar and Panchet reservoirs were constructed on Damodar River during 1955 and 1959, respectively. The drainage areas of Konar and Panchet catchments are 997.15 and $9880.85 \mathrm{~km}^{2}$, respectively.

The Shuttle Radar Topography Mission (SRTM) digital elevation model (DEM, $90 \mathrm{~m}$ resolution) was used to generate a stream network and the drainage pattern of the catchment. The minimum threshold value of 200 ha was used to generate the stream network and predefined watershed boundary map of Damodar catchment was overlaid on the delineated stream network. The outlet locations were assigned manually to delineate watersheds that resemble predefined watersheds in terms of area coverage and periphery. With this approach, 411 watersheds were delineated against previously manually delineated 472 watersheds by the DVC. Differences in number of watersheds occurred because many of the first-order streams were not extracted using the SRTM DEM. Figure 1 shows the location of Konar and Panchet reservoirs with Nagwan and Banikdih watersheds.

The soil maps and soil properties data of the study area were collected from the National Bureau of Soil Survey and Land Use Planning (NBSS\&LP) Kolkata, India. The soil of the study area is classified into three texture groups as sandy loam $(80.17 \%)$, sandy clay loam $(9.53 \%)$, and loamy sand $(10.3 \%)$. The LULC of the catchment is classified in five land use classes: agriculture (40.92\%), forest $(30.74 \%)$, wasteland $(19.13 \%)$, urban $(3.16 \%)$, water $(4.50 \%)$ and wetland $(1.55 \%)$ using Enhanced Thematic Mapper Plus (ETM+) remote sensing images of landsat-7 of 2000 (Row/path: 141/44, 140/43; date: 22.11.2000, 14.10.2000) and 2001 (Row/Path: 141/43, 140/44, 139/44; date: 25.01.2001, 02.11.2001, 26.11.2001).

\section{SWAT hydrological model}

The SWAT model is a process-based distributed hydrological model; it operates on a daily time step to simulate sediment and runoff at the watershed scale (Arnold et al. 1998; Arnold and Fohrer 2005) using the Soil Conservation Service (SCS) Curve Number (CN) method and Modified Universal Soil Loss Equation, respectively. The model is designed to route water and sediments from individual watersheds, through the river systems and can incorporate water bodies: ponds, wetlands, reservoirs and potholes with identical methods for water and sediment processes modeling. For details about the model, refer to the SWAT user manual (Neitsch et al. 2005). 


\section{Model calibration and validation}

The model calibration and validation was performed for the period of 1997-1999 and 2000-2001, respectively, with 2 years of warm-up period in each phase. Sensitivity analysis was performed for 30 parameters identified in the literature to have a potential influence on flow and sediment yield. Ranges of the parameters were based on the SWAT manual (Neitsch et al. 2005). The most sensitive parameters were selected for model calibration, including SCS curve number, Manning's roughness coefficient and hydraulic conductivity for runoff. For sediment simulation, the linear parameter of sediment routing capacity, linear re-entrainment parameter, exponent of re-entrainment parameter, and the Manning's roughness coefficient are the most sensitive parameters, highlighting the importance of channel processes to sediment yield. Then the model was calibrated for monthly runoff and sediment yield for two watersheds (Nagwan and Banikdih) for the monsoon season and inflow to Konar and Panchet reservoirs for both monsoon and non-monsoon seasons. After calibration, the model was validated for the 2 years (2000-2001) without changing the model parameters. Spatial land use and soil properties are assumed to be constant throughout the simulation period. Hargreaves method of evapotranspiration (ET) estimation is opted in this study because of two reasons: (1) availability of daily temperature data, and (2) recommendations given by Kannan et al. (2007) in which they showed that the combination of the curve number $(\mathrm{CN})$ method with Hargreaves methods of ET estimation gives good results in streamflow simulation.

The numerical and graphical performance criteria are used for performance evaluation of the model during calibration and validation period. The numerical performance criteria include percent bias (PBIAS), correlation coefficient (r), Nash-Sutcliffe coefficient (NS) and root mean square error (RMSE). These performance criteria can be estimated as:

$$
\begin{aligned}
& \text { PBIAS }=\frac{\sum_{i=1}^{n}\left(Y_{\mathrm{obs}, i}-Y_{\mathrm{sim}, i}\right)}{\sum_{i=1}^{n} Y_{\mathrm{obs}, i}} \times 100 \\
& r=\frac{\sum_{i=1}^{n}\left(Y_{\mathrm{obs}, i}-\bar{Y}_{\mathrm{obs}}\right)\left(Y_{\mathrm{sim}, i}-\bar{Y}_{\mathrm{sim}}\right)}{\sqrt{\sum_{i=1}^{n}\left(Y_{\mathrm{obs}, i}-\bar{Y}_{\mathrm{obs}}\right)^{2} \sum_{i=1}^{n}\left(Y_{\mathrm{sim}, i}-\bar{Y}_{\mathrm{sim}}\right)^{2}}} \\
& \mathrm{NS}=1-\frac{\sum_{i=1}^{n}\left(Y_{\mathrm{obs}, i}-Y_{\mathrm{sim}, i}\right)^{2}}{\sum_{i=1}^{n}\left(Y_{\mathrm{obs}, i}-\bar{Y}_{\mathrm{obs}}\right)^{2}} \\
& \mathrm{RMSE}=\sqrt{\frac{\sum_{i=1}^{n}\left(Y_{\mathrm{obs}, i}-Y_{\mathrm{sim}, i}\right)^{2}}{n}},
\end{aligned}
$$

where $Y_{\mathrm{obs}, i}$ and $Y_{\mathrm{sim}, i}$ are the observed and simulated hydrologic variables, respectively; whereas, $\bar{Y}_{\mathrm{obs}}$ and $\bar{Y}_{\text {sim }}$ are the average of observed and simulated hydrologic variables, respectively, and $n$ total number of data sets.

\section{Identification and prioritization of critical watersheds}

Variation in topography, soil, land use/cover, management conditions and rainfall characteristics over different parts of the catchment/watershed leads to variation in runoff and sediment yield. To control the sedimentation of water resources like reservoirs, better knowledge of hydrological processes of the watershed is required to identify critical erosion areas for developing effective management strategies. The validated model was used to simulate sediment yield during the study period (1997-2001) and the critical watersheds in which soil loss exceeded the tolerance limit of 5.0 ton/ha/year (Singh et al. 1992) were identified. Watersheds within the catchment are grouped into different classes based on the average annual soil loss and priority was assigned in which they have to be taken up for soil conservation measures in near future. First, to test the SWAT model appropriateness in identification of critical watersheds, the watersheds of the Damodar catchment were classified into three erosion classes, i.e., low (0-5 ton/ha/year), medium (5-20 ton/ha/year) and high ( $>20$ ton/ha/year) following the criteria proposed by Deore (2005). The SWAT-simulated spatial distribution of erosion classes was compared with spatial distribution of erosion classes prepared by DVC. DVC used a method proposed by Karale et al. (1977) to classify 716 watersheds located in upper Damodar catchment into three classes, namely, low, medium and high using the sediment yield index. Sediment yield index is a function of weighted average erosion intensity and sediment delivery ratio. The different soil erosion classes of DVC survey are compared with the SWAT-derived erosion classes with the overlapping of the maps. After testing the appropriateness of the SWAT model in identifying critical watersheds, the simulated average annual sediment yield during the study period from watersheds was used to prioritize the watersheds in seven new classes for prioritizing management strategy to reduce reservoir sedimentation. The new classes had an average annual sediment rate of $>40,30-40,25-30,20-25,15-20$ and 5-15 and 0-5 ton/ha/year. The prioritized watersheds were considered for management in a sequential manner as described below.

\section{Management of critical erosion-prone watersheds and reservoir sedimentation rate}

Management of critical erosion watersheds requires adaptation of effective management practices to reduce soil 
erosion and sediment transport to the stream network and finally to water bodies. In practice, to control soil erosion problem in the study area, SCD Hazaribagh has initiated different management practices which includes construction of bunds, farm pond, check dams, etc. In the SWAT model these management practices are represented by considering farm pond in the watershed. Conservation practices such as contour bunding, graded bunding, strip cropping and terracing are represented using the weighted values of USLE support practice factor on the basis of slope factor. Plantation and agricultural practices are accounted through cover factor, curve number and conventional tillage. To treat the watersheds, which are under high and medium erosion risk classes, seven different management stages (based on critical sediment generation rate) were considered on the basis of average annual sediment yield. Each watershed is assigned priority according to its average sediment loss magnitude, except priority one (P-I) (watershed with high erosion surrounding the reservoirs). Priority one watersheds are to be treated first and thereafter, watersheds with an average annual sediment rate of $>40$ (P-II), 30-40 (P-III), 25-30 (P-IV), 20-25 (P-V), 15-20 (P-VI) and 5-15 (P-VII) ton/hectare/year, respectively, have been taken for treatment in a sequential manner. In all seven management stages, farm pond is added to every watershed and weighted conservation practice factor was changed in the management practices of agricultural area.

To estimate the useful life of Konar and Panchet reservoirs, the inflow and outflow sediment concentration in and from the reservoirs before and after treatment of watersheds was analyzed in sequential. The life of reservoirs was estimated using the procedure adopted in the sedimentation study of Konar reservoir (CWC 1996). This study uses Brune (1953) curve approach which correlates the trap efficiency of a reservoir to its capacity inflow $(\mathrm{C} / \mathrm{I})$ ratio. The sediment deposition rate is computed by multiplying sediment inflow rate with the estimated trap efficiency. Percent silt deposition at full dead storage is determined from location curve and the volume of total silt trapped in the reservoir is determined by dividing the dead storage capacity by percent silt deposition. The life of the reservoir at dead storage level is determined by dividing the volume of sediment by the sediment deposition rate. Similarly, reservoir life at spillway elevations is also determined. The life of the reservoir is calculated for all the sequential conservation treatments. The present study is more concerned with the life up to the spillway level, because until this level there may not be any difficulty in the operation of the reservoir gates; however, the useful capacity is reduced.

\section{Results and discussion}

\section{Calibration and validation of SWAT model}

The model is calibrated and validated for the monsoon season (June-September) for runoff and sediment yield at the outlets of Nagwan and Banikdih watersheds. The calibrated values of Manning's $n$ for overland flow, Manning's $n$ for channel flow, and effective hydraulic conductivity of channel alluvium is found to be $0.10,0.09$ and $2.0 \mathrm{~mm} / \mathrm{h}$ for Nagwan and $0.068,0.21$ and $6.70 \mathrm{~mm} / \mathrm{h}$ for Banikdih watersheds, respectively. The curve number for Nagwan and Banikdih varies from 49 to 67 and 73 to 81 , respectively, with surface lag time of one day for both the watersheds. In addition, sediment routing factor, linear reentrainment parameter and exponent of re-entrainment parameter (coefficients of sediment routing equation for channel sediment routing) are found to be $0.10,0.02$ and 1.3 , respectively. These values are in close agreement with Betrie et al. (2011) reported values of routing factor as 0.12 , linear parameter as 0.01 and exponent as 1.20 in sediment routing equation. The results of the model calibration and validation for runoff, sediment yield and reservoir inflow are presented below.

\section{Runoff}

Comparison between observed and simulated monthly runoff for calibration and validation periods is shown in Fig. 2a, b, respectively, for Nagwan and Banikdih watersheds. The magnitude and temporal variation of simulated runoff are in reasonable agreement with the observed runoff for the entire monsoon seasons for both the watersheds. It has been observed from the graphical comparisons of the two watersheds that during the beginning of the monsoon season, i.e., June, the model slightly under-predicts runoff. This may be due to the low initial soil moisture condition and higher storage loss condition, but overall graphical comparison of model performance has been found satisfactory as indicated by close agreement between measured and simulated values of runoff for the two watersheds located in the Damodar catchment. The descriptive statistics for calibration and validation periods for Nagwan and Banikdih are presented in Table 1. The maximum values of runoff are over predicted by the model for both the watersheds varying between 10.15 and $19.03 \mathrm{~mm}$ during the calibration and validation periods. Overall, the maximum, average and standard deviation values of observed and simulated runoff are in close agreement. The PBIAS between observed and simulated runoff is higher in case of Nagwan as compared to Banikdih during calibration period. 
Fig. 2 Simulated monthly surface runoff during calibration (1997-1999) and the validation (2000-2001) period in Damodar catchment for Nagwan (a) and Banikdih (b) watersheds

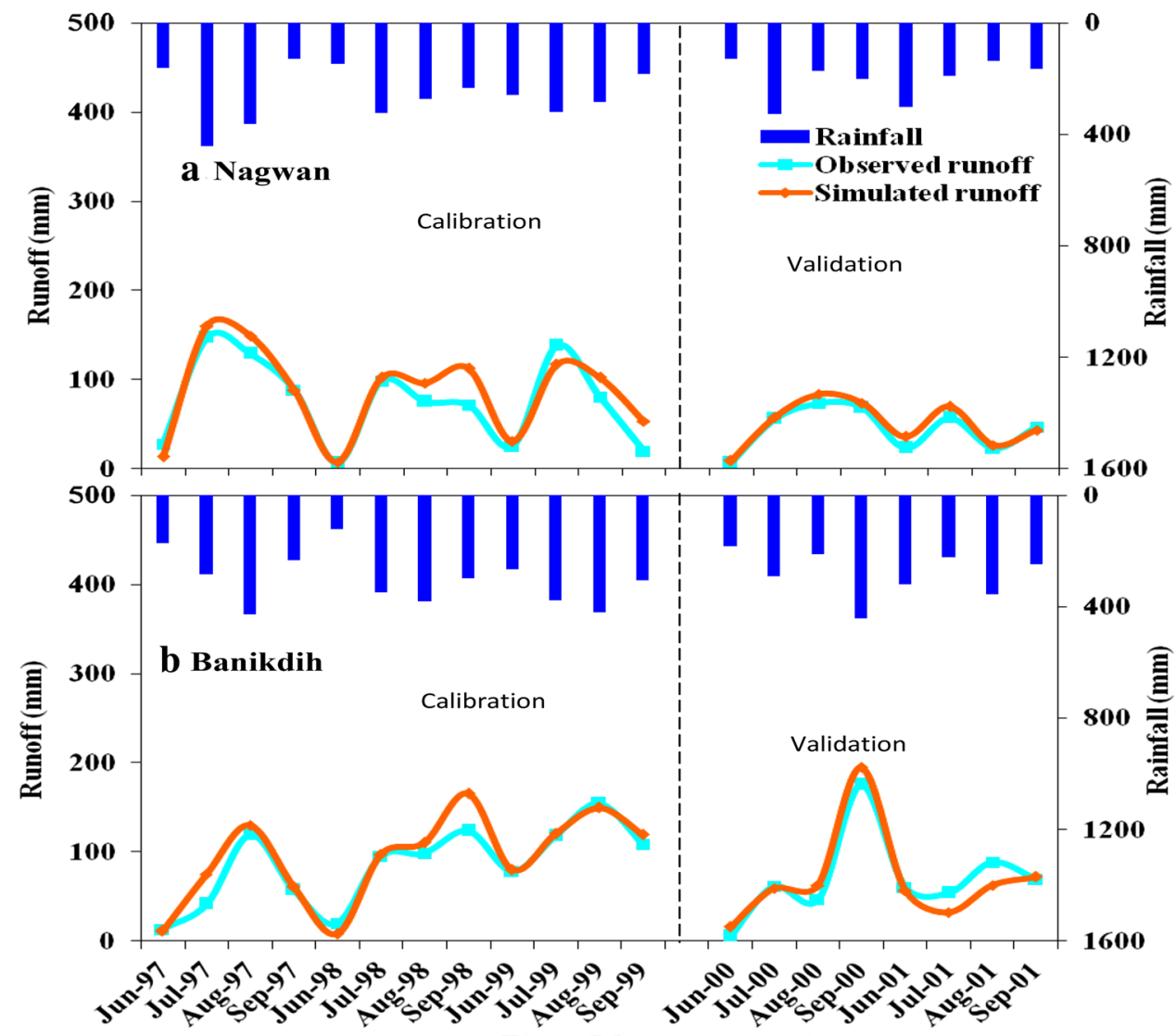

Time (Monsoon season)
However, the PBIAS is within the acceptable limit of $\pm 15 \%$ (Moriasi et al., 2007) and in accordance with the reported results of $11.73 \%$ deviation by Mishra and Kar (2012) in stream flow simulation for Banha watershed in Barakar catchment of DVC. On the other side, low RMSE values between 7.60 and $20.36 \mathrm{~mm}$ for Banikdih and Nagwan during calibration and validation, reflected close agreement between measured and simulated monthly runoff. Higher values of $r$ and $N S$ for both the watersheds (Table 1) during calibration $(0.81-0.91 ; 0.84-0.87$, respectively) and validation (0.91-0.95; 0.88 , respectively) indicate that the model is able to simulate both the pattern and magnitude of the runoff during the monsoon season. These results indicate that the present calibration and validation of the model for runoff is good and acceptable on the basis of statistics suggested by Moriasi et al. (2007).

\section{Sediment yield}

The observed and simulated monthly sediment yield (monsoon season) for the calibration and validation periods is compared graphically for Nagwan and Banikdih watersheds and is shown in Fig. 3a, b. Simulated sediment yield
Table 1 Statistical comparison between observed and simulation runoff $(\mathrm{mm})$ during the monsoon months at Nagwan and Banikdih watersheds during calibration and validation period

\begin{tabular}{|c|c|c|c|c|c|c|c|c|}
\hline \multirow[t]{3}{*}{ Statistical parameters } & \multicolumn{4}{|c|}{ Nagwan watershed } & \multicolumn{4}{|c|}{ Banikdih watershed } \\
\hline & \multicolumn{2}{|c|}{ Calibration } & \multicolumn{2}{|c|}{ Validation } & \multicolumn{2}{|c|}{ Calibration } & \multicolumn{2}{|c|}{ Validation } \\
\hline & Obs. & Sim. & Obs. & Sim. & Obs. & Sim. & Obs. & Sim. \\
\hline Average runoff $(\mathrm{mm})$ & 75.65 & 85.97 & 44.40 & 49.87 & 85.69 & 93.95 & 70.23 & 69.52 \\
\hline Standard deviation $(\mathrm{mm})$ & 48.07 & 49.85 & 24.04 & 25.72 & 44.27 & 49.48 & 48.69 & 53.96 \\
\hline Maximum $(\mathrm{mm})$ & 147.30 & 160.08 & 73.30 & 83.45 & 154.30 & 165.50 & 175.60 & 194.63 \\
\hline RMSE (mm) & 20.36 & & 7.60 & & 16.83 & & 15.50 & \\
\hline Correlation coefficient $(r)$ & 0.86 & & 0.95 & & 0.91 & & 0.91 & \\
\hline Nash-Sutcliffe coefficient (NS) & 0.87 & & 0.88 & & 0.84 & & 0.88 & \\
\hline Percent bias (PBIAS) & 13.64 & & 12.32 & & 9.63 & & -1.01 & \\
\hline
\end{tabular}


follows the pattern of the observed sediment during the entire monsoon season except for few months. In the staring month of monsoon season, i.e., June, the simulated sediment yield is under-predicted by the model, same as in case of runoff. It is also observed from the graphical comparison that the model under-predicts the sediment yield for most of the monsoon months in two watersheds, which may be because of rainfall characteristics and SWAT model approach of sediment estimation based on the total quantity of rainwater rather than the intensity in the specific period. The slight differences may be attributed to conservation measures adopted during the years in both the watersheds. The sediment yield has direct relationship with runoff and hence it has been observed that sediment yield also follows the pattern of simulated runoff. The descriptive statistics for calibration and validation periods for both the watersheds are presented in Table 2. The maximum sediment yield was over predicted by the model for the Nagwan watershed and under-predicted for the Banikdih watershed, but the average sediment yield and standard deviation are in close agreement for both the watersheds. The statistics indicate a close agreement between observed and simulated sediment yield from watersheds as indicated by quite high values of $r(0.81-0.87)$ and
NS (0.76-0.85) for the calibration and validation periods. The low value of RMSE (0.12-0.27 ton/ha) indicates that the model well simulates the peak values of sediment yield during the calibration and validation. In all cases, deviation between the observed and simulated sediment yield is much less than $\pm 15 \%$ which indicate that the model predicts sediment yield reasonably well in both the watersheds. Based on review study performed by Moriasi et al. (2007), the results are well within the acceptable range of accuracy and the model can be used for further study. After the successful calibration and validation of SWAT model for Nagwan and Banikdih watersheds, the calibrated model parameters are up-scaled to other watersheds with respect to reservoir's sub-catchment (Nagwan for Konar sub-catchment, and Banikdih for Panchet subcatchment) and then calibration and validation of the reservoir inflows was done. The results for reservoirs inflow are discussed as below.

\section{Reservoir inflow}

Comparison between observed and simulated inflow to Konar and Panchet reservoirs for the calibration and validation periods is shown in Fig. $4 \mathrm{a}, \mathrm{b}$. Calibration of
Fig. 3 Simulated monthly sediment yield during calibration (1997-1999) and validation (2000-2001) period in Damodar catchment at Nagwan (a) and Banikdih (b) watersheds

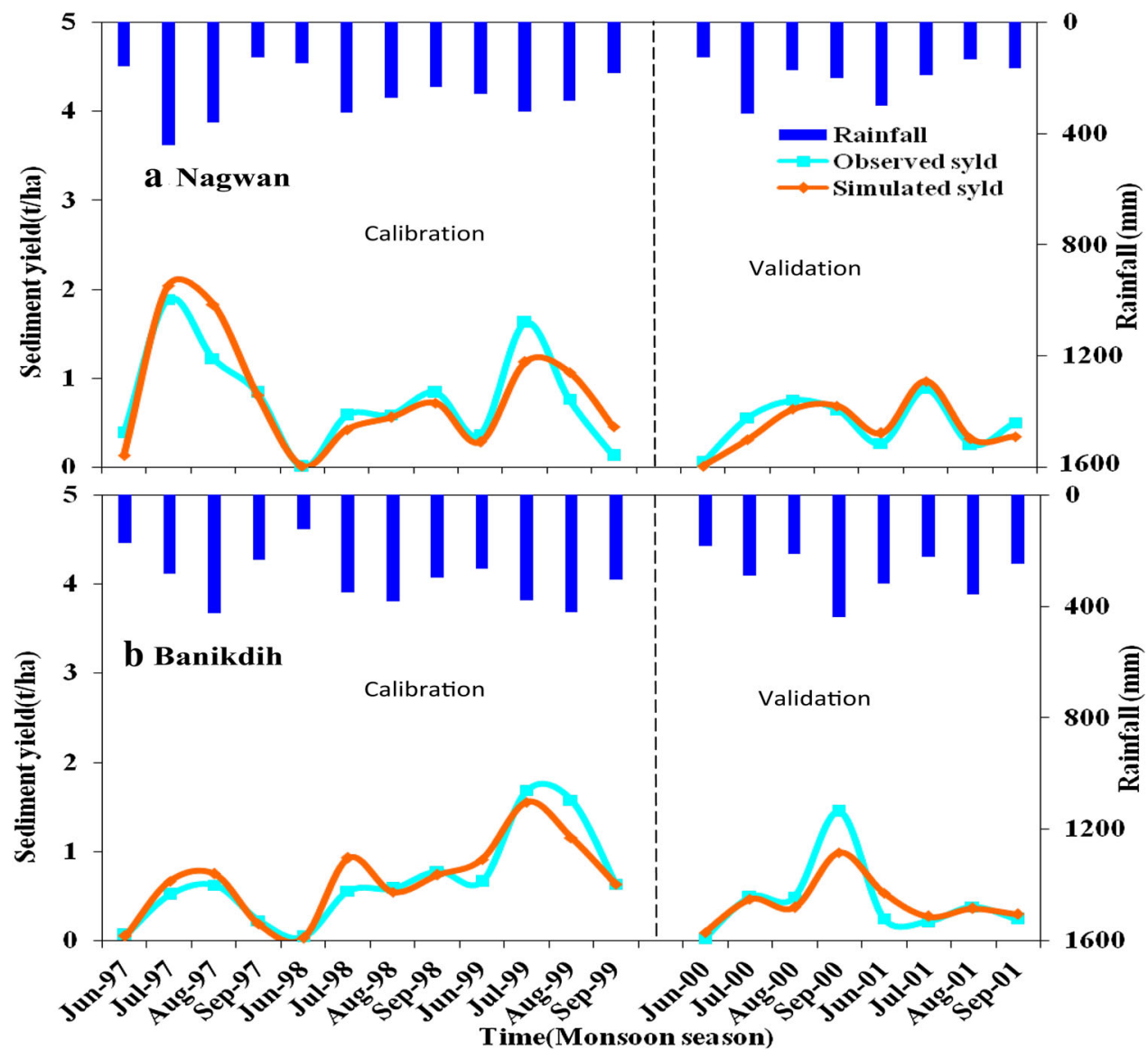


Table 2 Statistical comparison between observed and simulated sediment yield (ton/ha) during the monsoon months at Nagwan and Banikdih watersheds for calibration and validation period

\begin{tabular}{|c|c|c|c|c|c|c|c|c|}
\hline \multirow[t]{3}{*}{ Statistical parameters } & \multicolumn{4}{|c|}{ Nagwan watershed } & \multicolumn{4}{|c|}{ Banikdih watershed } \\
\hline & \multicolumn{2}{|c|}{ Calibration } & \multicolumn{2}{|c|}{ Validation } & \multicolumn{2}{|c|}{ Calibration } & \multicolumn{2}{|c|}{ Validation } \\
\hline & Obs. & Sim. & Obs. & Sim. & Obs. & Sim. & Obs. & Sim. \\
\hline Average sediment yield (ton/ha) & 0.77 & 0.79 & 0.49 & 0.46 & 0.66 & 0.68 & 0.44 & 0.42 \\
\hline Standard deviation (ton/ha) & 0.57 & 0.64 & 0.28 & 0.29 & 0.51 & 0.45 & 0.44 & 0.26 \\
\hline Maximum (ton/ha) & 1.88 & 2.04 & 0.88 & 0.97 & 1.68 & 1.55 & 1.44 & 0.99 \\
\hline RMSE (ton/ha) & 0.27 & & 0.12 & & 0.19 & & 0.20 & \\
\hline Correlation coefficient $(r)$ & 0.81 & & 0.81 & & 0.85 & & 0.87 & \\
\hline Nash-Sutcliffe coefficient (NS) & 0.80 & & 0.81 & & 0.85 & & 0.76 & \\
\hline Percent bias (PBIAS) & 3.09 & & -5.67 & & 2.79 & & -4.28 & \\
\hline
\end{tabular}

Konar reservoir was done first as outflow of Konar reservoir finally drains into Panchet catchment. For both the reservoirs, simulated monthly inflow during the monsoon and non-monsoon months matched well with their observed counterparts. However, the model under-predicts the reservoir during the starting of calibration period. This may be due to difference in initial conditions between the model and catchment condition. The warm-up period of 2 years may not be sufficient to initialize actual conditions. A longer warm-up period may solve this problem of under predication in early phase. A few peaks are under or over simulated by the model, which may be due to initial differences in actual and model simulated storage, temporal storage and soil moisture conditions in the catchment. The variation may also be attributed to two weather station used for simulating the hydrological processes in the large catchment area $\left(10,878 \mathrm{~km}^{2}\right)$ divided into 411 watersheds, which may have not well captured the spatial variability of rainfall over the area. Use of more weather stations may give better representation of areal rainfall. Overall simulated inflow for the two reservoirs has a linear relationship with measured inflow. Table 3 presents the statistical summary of comparison between the observed and simulated inflows during the calibration and validation periods for both reservoirs. During calibration, over-prediction is observed in total inflow in case of Konar and under-prediction in case of Panchet reservoir and vice versa during the validation period. In case of Panchet reservoir, under-prediction of inflow may be due to the presence of Konar reservoir and other water harvesting structures like check dams, farm ponds, etc., in the upstream. Although outflow from Konar is taken into account, unavailability of data pertaining to structures influence may be one reason for under- and over-prediction in total inflow in both the reservoirs. Quite high values of $r(0.82-0.86)$ and $N S(0.81-0.95)$ coefficient during the calibration and validation periods indicate an appropriate simulation of trend and peak values of inflow in both the reservoirs. Low RMSE (between 7.84 and $50.95 \mathrm{~m}^{3} / \mathrm{s}$ ) values indicate that the model simulates observed values reasonably well during the calibration and validation periods. On the other side, low value of PBIAS (between 16.77 and -8.21\%) indicates that the model is predicting reservoir inflow within the acceptable limit of accuracy as suggested by Moriasi et al. (2007).

\section{Identified critical watersheds of Damodar catchment}

The critical watersheds were identified on the basis of average annual sediment yield obtained from the model output for the study period. First, to test the model appropriateness, watersheds were classified into three erosion classes (low, medium and high) and compared with manual classification of critical watersheds performed by SCD. Figure 5a, b shows classified watersheds maps. The model delineated 411 watersheds against manually delineated 472 watersheds by SCD, Hazaribagh. Out of these, 277 watersheds fall under high, 84 watersheds under medium and 50 watersheds under low soil erosion class based on model simulation results. On the other hand, SCD data shows that, 317, 94 and 61 watersheds fall under high, medium and low soil erosion classes, respectively. The spatial distribution of different erosion classes, performed by using SWAT model, matched well with manually defined erosion classes. Because of difference in the number of delineated watersheds by SWAT model and DVC, the area under different erosion classes was compared using GIS tools. Table 4 shows the comparison of area under different erosion classes with DVC priority. From the analysis, $80.60 \%$ prioritized area between SWAT model and DVC is exactly same but $19.40 \%$ area has spatial mismatch. For example, 5956.99, 1637.48 and $1085.63 \mathrm{~km}^{2}$ area classified under high, medium and low soil erosion classes using SWAT model as well as the manual classification of DVC, have the same spatial boundaries. The rest of the area showed mismatch between spatial distribution of erosion classes. However, the total classified area under three classes, using model as well as manual approach (DVC), is 
Fig. 4 Monthly simulated reservoir inflow during calibration (1997-1999) and the validation (2000-2001) period in Damodar catchment for Konar (a) and Panchet (b) reservoirs
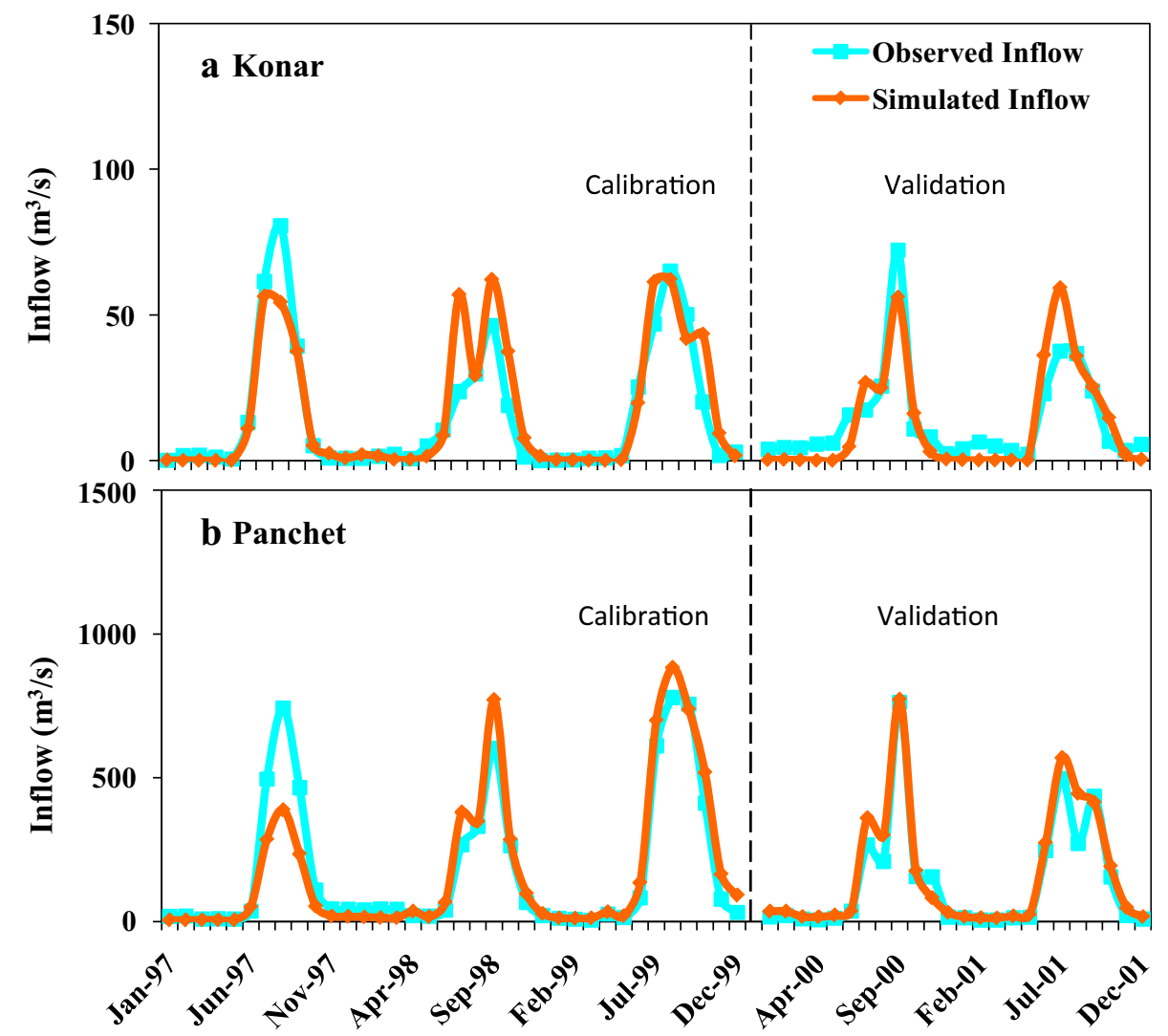

Time (months)
Table 3 Statistical comparison between observed and simulated reservoir inflows during calibration and validation period for Konar and Panchet reservoirs

\begin{tabular}{|c|c|c|c|c|c|c|c|c|}
\hline \multirow[t]{3}{*}{ Statistical parameters } & \multicolumn{4}{|l|}{ Konar } & \multicolumn{4}{|l|}{ Panchet } \\
\hline & \multicolumn{2}{|c|}{ Calibration } & \multicolumn{2}{|c|}{ Validation } & \multicolumn{2}{|c|}{ Calibration } & \multicolumn{2}{|c|}{ Validation } \\
\hline & Obs. & Sim. & Obs. & Sim. & Obs. & Sim. & Obs. & Sim. \\
\hline Average inflow $\left(\mathrm{m}^{3} / \mathrm{s}\right)$ & 15.66 & 17.13 & 13.95 & 12.80 & 182.73 & 179.46 & 140.09 & 163.59 \\
\hline Standard deviation $\left(\mathrm{m}^{3} / \mathrm{s}\right)$ & 22.25 & 22.88 & 16.31 & 18.39 & 250.17 & 252.20 & 195.21 & 211.28 \\
\hline $\operatorname{Maximum}\left(\mathrm{m}^{3} / \mathrm{s}\right)$ & 80.56 & 62.11 & 72.33 & 59.20 & 778.92 & 882.60 & 763.63 & 772.00 \\
\hline $\operatorname{RMSE}\left(\mathrm{m}^{3} / \mathrm{s}\right)$ & 9.73 & & 7.84 & & 93.90 & & 50.95 & \\
\hline Correlation coefficient $(r)$ & 0.82 & & 0.81 & & 0.86 & & 0.95 & \\
\hline Nash-Sutcliffe coefficient (NS) & 0.80 & & 0.76 & & 0.86 & & 0.93 & \\
\hline Percent bias (PBIAS) & 9.42 & & -8.21 & & -1.79 & & 16.77 & \\
\hline
\end{tabular}

almost same. At this stage, it is assumed that SWAT model is well simulating the hydrological process in the Damodar catchment. For the management purposes, the critical erosion watersheds were again classified into seven different classes (Fig. 6) as discussed in the "Materials and methods" section. Management of these watersheds has been taken up sequentially. The findings before and after management adaptation, on annual sediment inflow into reservoir, reservoir sedimentation and reservoir life are discussed below.

\section{Reservoir sedimentation rate and life}

The simulated sediment inflow into reservoir and reservoir sedimentation rate, as an impact of sequentially implemented conservation measures in watersheds corresponding to seven management stages, are presented in Fig. 7 for both reservoirs. The results show that the magnitude of sediment inflow as well as deposition rate in the Konar reservoir is much less as compared to Panchet reservoir. This is because of the location of Panchet reservoir which 
Fig. 5 Prioritized watersheds of Damodar catchment using DVC manual approach (a), and using SWAT modeling approach (b)
Table 4 Summarized classification of area under different classes by SWAT model and their comparison with DVC classes

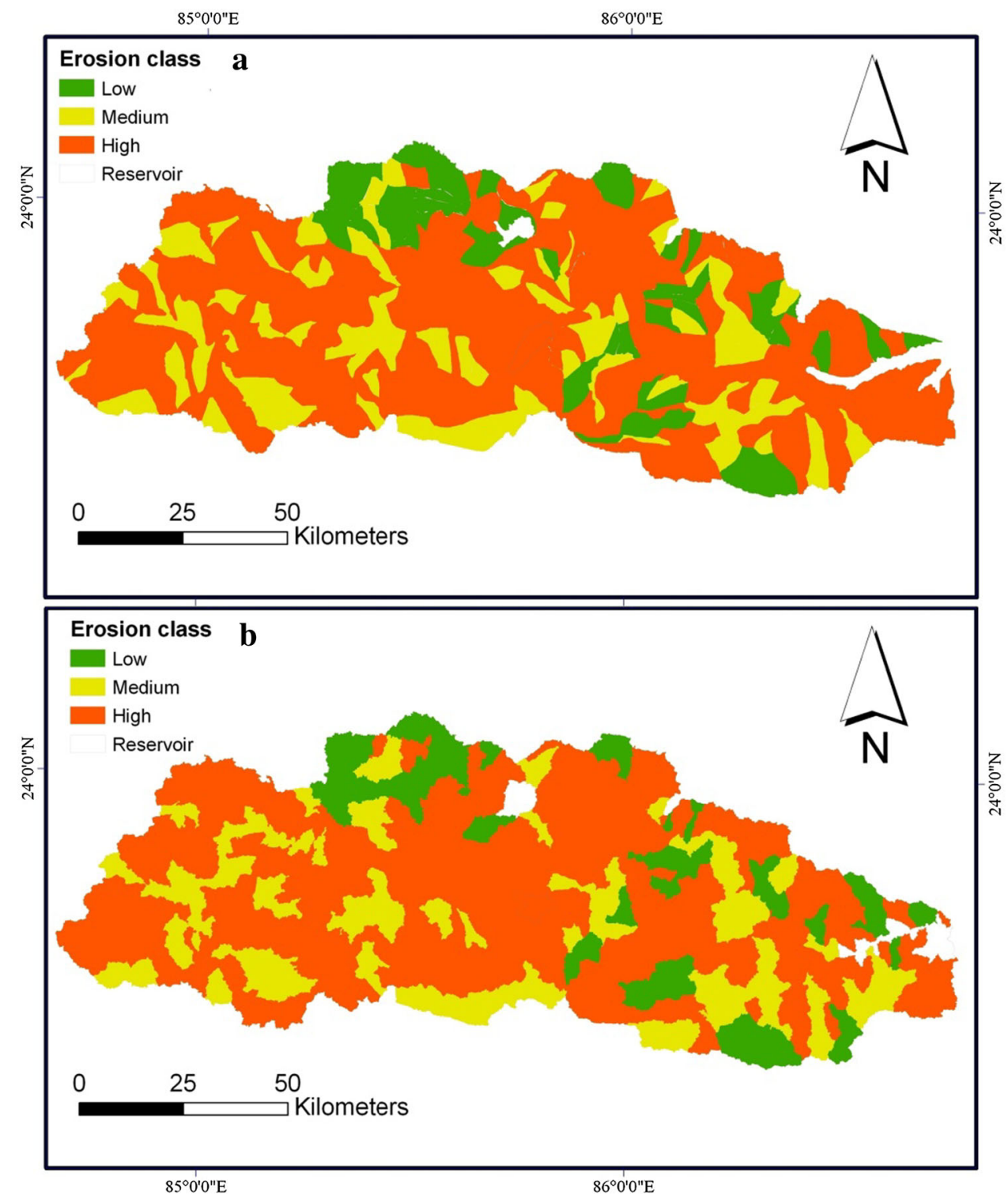

\begin{tabular}{llcccc}
\hline Sr. no. & SWAT/DVC $\left(\mathrm{Km}^{2}\right)$ & High $\left(\mathrm{km}^{2}\right)$ & Medium $\left(\mathrm{km}^{2}\right)$ & Low $\left(\mathrm{km}^{2}\right)$ & SWAT Total $\left(\mathrm{km}^{2}\right)$ \\
\hline 1 & High & 5956.99 & 674.99 & 285.88 & 6917.86 \\
2 & Medium & 754.05 & 1637.48 & 85.86 & 2477.38 \\
3 & Low & 208.97 & 79.12 & 1085.63 & 1373.72 \\
4 & DVC Total & 6920.02 & 2391.59 & 1457.37 & $10,768.97$ \\
\hline
\end{tabular}

receives outflow from Konar reservoir as well as from large catchment. The average sediment inflow, before adaptation to management, has been simulated as 1.19 and $4.32 \mathrm{Mm}^{3} /$ year, respectively, for Konar and Panchet, which have been reduced to, respectively, 1.04 and $2.13 \mathrm{Mm}^{3} /$ year after adaptation to management strategy in the catchment. The SWAT-simulated sedimentation rate, before adaptation of conservation measures, was $1.12 \mathrm{Mm}^{3} /$ year for the Konar, which is less in comparison with the sedimentation rate (1.75 $\mathrm{Mm}^{3} /$ year) estimated by CWC (1998). For the Panchet reservoir, the SWAT-simulated sedimentation rate of $3.65 \mathrm{Mm}^{3} /$ year is quite close $\left(3.40 \mathrm{Mm}^{3} /\right.$ year $)$ as estimated by CWC (1996).

To simulate the effect of management practices (soil and water conservation measures) on reservoir sedimentation rate and life, a management plan was sequentially 
Fig. 6 Prioritized watersheds of Damodar catchment showing seven erosion classes using SWAT simulations for study period
$85^{\circ} 0^{\prime} 0^{\prime \prime} \mathrm{E}$
$86^{\circ} 0^{\prime} 0^{\prime \prime} \mathrm{E}$

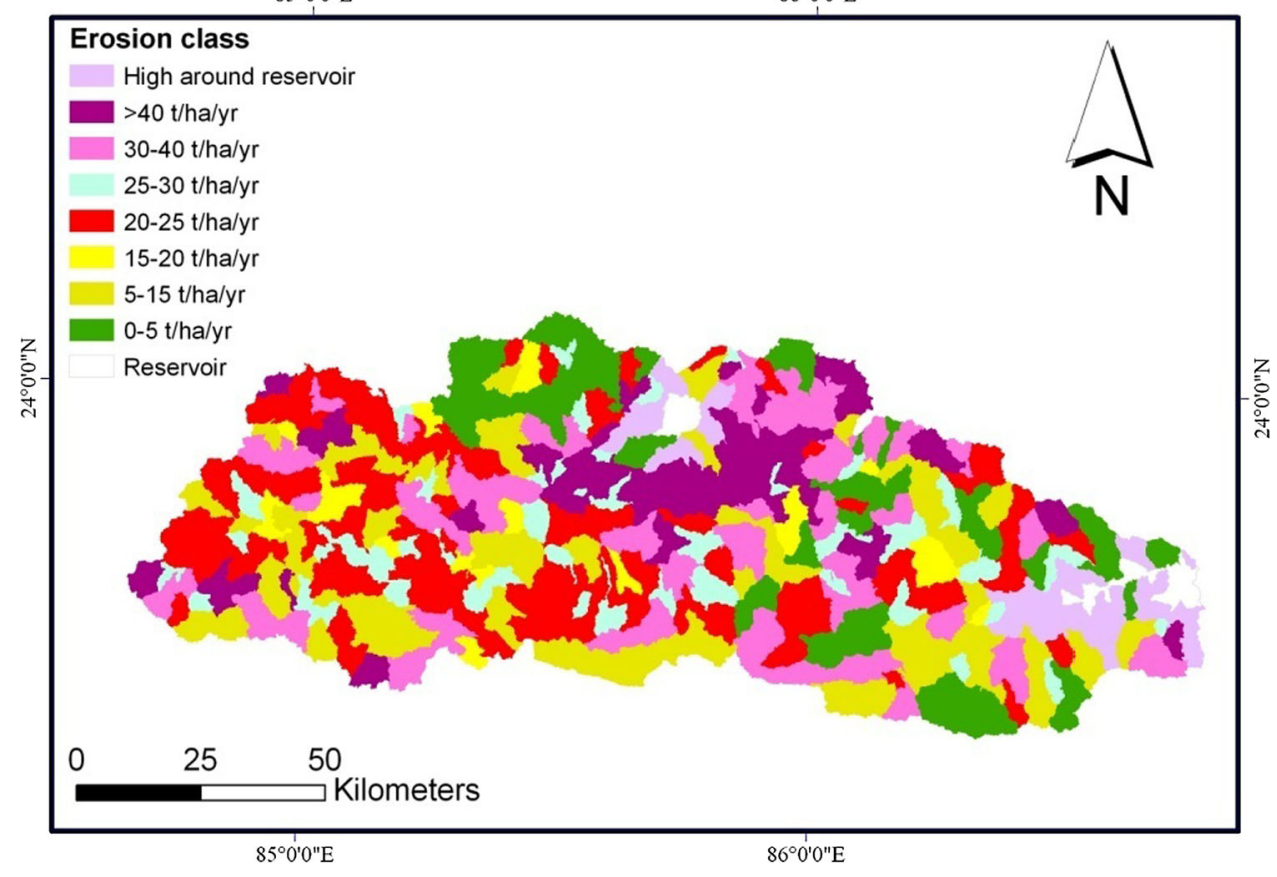

Fig. 7 Sediment inflow and reservoir sedimentation corresponding to nomanagement and seven sequential management scenarios in Konar and Panchet reservoirs

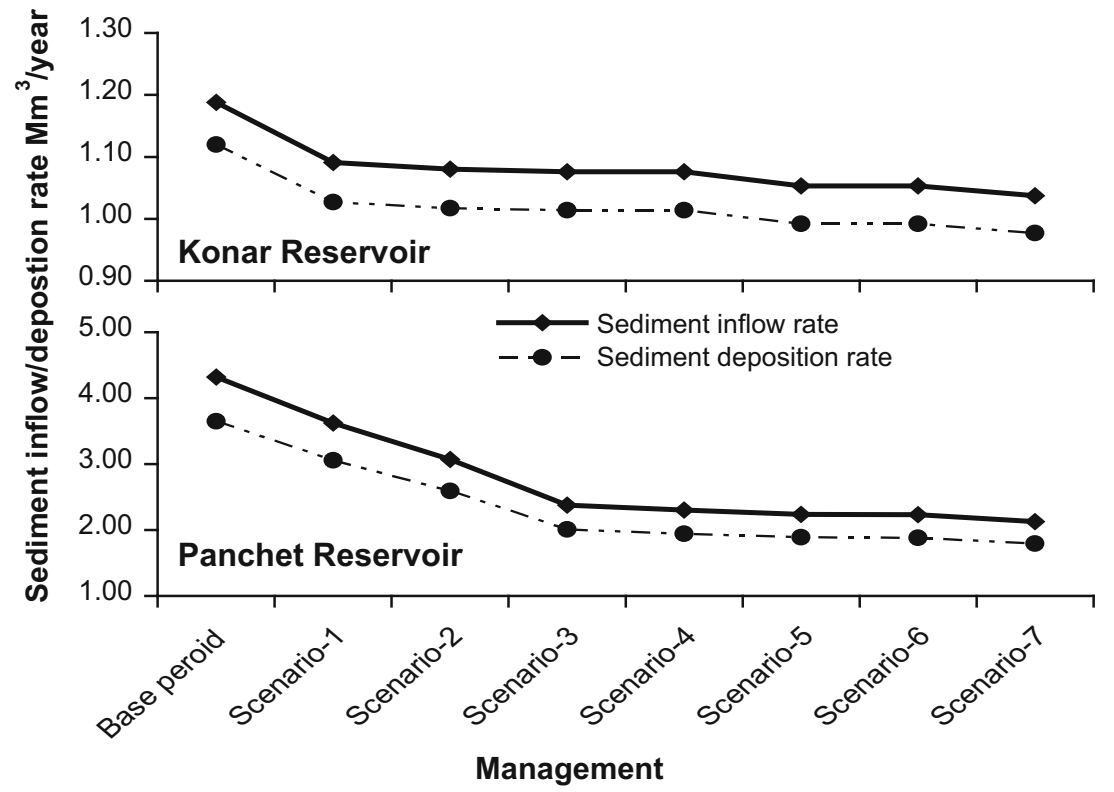

implemented in the critical watersheds considering assignment of their priority based on proximity of watersheds to reservoirs and average annual sediment loss. The highpriority watersheds in the vicinity of the reservoir were treated first and watersheds having an average annual sediment loss >40, 30-40, 25-30, 20-25, 15-20 and 5-15 ton/ha/year, respectively, were taken up sequentially for treatment. Their impact on reservoir sedimentation was studied. Simulation results showed that the sedimentation rate decreased from the current rate of 1.12 and $3.65 \mathrm{Mm}^{3}$ / year to 0.98 and $1.80 \mathrm{Mm}^{3} /$ year for Konar and Panchet reservoirs, respectively (Fig. 7). Table 5 shows the increase in reservoir's useful life, up to spillway storage level, from the reference year of 1997 based on sequential treatment of watersheds pertaining to the priority class. The estimated life of the Konar reservoir without management adaptation is 97 years. With management scenario P-I (treating the high-priority watersheds around the reservoir) life is increased to 100 years. However, the reservoir would take 105 years to get filled up to spillway level when all 
Table 5 Total reservoir life and percent increment in the reservoir life from study period for the Konar and Panchet reservoirs following the sequential conservation management scenarios in Damodar catchment

\begin{tabular}{|c|c|c|c|c|c|}
\hline \multirow[t]{2}{*}{ Management scenario } & \multirow[t]{2}{*}{ No of watersheds treated } & \multicolumn{2}{|l|}{ Konar } & \multicolumn{2}{|l|}{ Panchet } \\
\hline & & $\begin{array}{l}\text { Total life } \\
\text { from } 1997\end{array}$ & $\begin{array}{l}\text { Percent increment } \\
\text { in life }\end{array}$ & $\begin{array}{l}\text { Total life } \\
\text { from } 1997\end{array}$ & $\begin{array}{l}\text { Percent increment } \\
\text { in life }\end{array}$ \\
\hline Study period & & 97 & & 117 & \\
\hline P-I & 26 & 100 & 3.09 & 118 & 0.85 \\
\hline P-II & 47 & 101 & 4.12 & 139 & 18.80 \\
\hline P-III & 54 & 101 & 4.12 & 180 & 53.85 \\
\hline P-IV & 61 & 101 & 4.12 & 185 & 58.12 \\
\hline $\mathrm{P}-\mathrm{V}$ & 92 & 104 & 7.22 & 191 & 63.25 \\
\hline P-VI & 19 & 104 & 7.22 & 192 & 64.10 \\
\hline P-VII & 62 & 105 & 8.25 & 202 & 72.65 \\
\hline
\end{tabular}

watersheds are treated up to management scenario P-VII. This shows an increase in the life of about $8.25 \%$ with respect to reference year 1997 . The analyzed marginal increase only is due to the fact that most of the watersheds in the Konar catchment are already saturated with respect to soil conservation.

The life of Panchet reservoir up to the spillway, under the study period condition, estimated as 117 years, which increases to 139 years (an increase of $18.80 \%$ ) when scenarios P-I and scenario P-II are implemented. During scenario P-III, maximum increment in life is estimated to 180 years $(53.85 \%$ increase compared to study period condition in 1997). This might be because of treatment of maximum number of watersheds generating high sediment yield in the catchment. Sequentially increasing the conservation management from scenario P-IV to P-VII, the increment in the life of Panchet reservoir is less as compared to other scenarios because these scenarios have medium-priority watersheds. Overall results show increment in the life of both the reservoirs because of management scenarios implementation in the catchment. Adaptation of management plan in the catchment resulted in additional increment in the life of Konar and Panchet reservoirs by 8 and 85 years, respectively. These results clearly indicate that the SWAT model can be used for identification and management of critical erosion areas to control sediment inflow to reservoir.

\section{Conclusions}

With the application of SWAT model, runoff, sediment yield and reservoir inflow were simulated in Damodar catchment. Calibration and validation results of the model show that simulated monthly runoff, sediment yield and reservoir inflow were in reasonable agreement with observed counterparts with PBIAS less than $\pm 16.77 \%$ in all cases. The low RMSE values of runoff (between 7.60 and $20.36 \mathrm{~mm}$ ), sediment yield (between 0.12 and 0.27 ton/ha) and reservoir inflow (between 7.84 and $50.95 \mathrm{~m}^{3} / \mathrm{s}$ ) indicating that the model is well simulating the observed values. On the other hand, higher values of $r$ (varying between 0.81 and 0.95 ) and NS (varying between 0.76 and 0.93 ) indicate that the model is well simulating the pattern and peak values of runoff, sediment yield and reservoirs inflow corresponding to the observed values. The identification of critical watersheds was done on the basis of average annual sediment yield obtained from the model simulations for the period 1997-2001. Out of 411 watershed, 277, 84 and 50 watersheds fall under high, medium and low erosion classes, respectively. The SWAT-simulated spatial distribution of different erosion classes matched well $(80.60 \%$ area) with the DVC reported erosion classes. The average sediment deposition rate calculated using the SWAT model simulations for the period of 1997-2001 is found to be close to the average annual sediment deposition rates estimated by CWC for Konar and Panchet reservoirs. Adaptation of sequential conservation measures pertaining to identified critical watersheds in the catchment resulted in decrease in reservoir sedimentation rate from the current rate of 1.12 and $3.65 \mathrm{Mm}^{3} /$ year to 0.98 and $1.80 \mathrm{Mm}^{3} /$ year for Konar and Panchet reservoirs, respectively. However, these conditions may alter in future if there is any change in land use/cover, rainfall pattern, agriculture and human activities in the area. The study shows that the SWAT model can be successfully used for identifying the critical watersheds in the Damodar catchment where direct observations are not possible, and their effect on the sedimentation rate and reservoirs' useful life. This modeling methodology will be helpful in a data-scarce environment; where a full survey of the catchment and installation of gauging stations is not possible in every watershed. A study such as this may also serve as a quick and accurate tool in identification of critical erosion 
watersheds, reservoirs' sedimentation rate and their useful life in contrast to traditional survey-based methods, which are time-consuming.

Acknowledgments The authors are grateful to the Soil Conservation Department, Damodar Valley Corporation, Hazaribagh, Jharkhand, India, and Indian Institute of Technology, Kharagpur, West Bengal, India, for funding the research.

\section{References}

Arnold JG, Fohrer N (2005) SWAT 2000: current capabilities and research opportunities in applied watershed modeling. Hydrol Process 19(3):563-572

Arnold JG, Srinivasan R, Muttiah RS, Williams JR (1998) Large area hydrologic modeling and assessment. Part 1: Model development. J Am Water Resour Assoc 34(1):73-89

Behera S, Panda RK (2006) Evaluation of management alternatives for an agricultural watershed in the sub-humid subtropical region using a physical process based model. Agric Ecosyst Environ 113:62-72

Betrie GD, Mohamed YA, Van Griensven A, Srinivasan R (2011) Sediment management modeling in the Blue Nile Basin using SWAT model. Hydrol Earth Syst Sci 15:807-818

Bracmort KS, Arabi M, Frankenberger JR, Engel BA, Arnold JG (2006) Modeling long-term water quality impact of structural BMPs. Trans ASABE 49(2):367-374

Brune GM (1953) Trap efficiency of reservoirs. Trans Am Geophys Union 34(3):407-418

Cantelli A, Paola C, Parker G (2004) Experiments on upstream migrating erosional narrowing and widening of an incisional channel caused by dam removal. Water Resour Res 40:1-12

Central Water Commission (1996) Capacity survey of Panchet reservoir. India

Central Water Commission (1998) Capacity survey of Konar reservoir. India

Damodar Valley Coporation (DVC) (2007) Land use report. Soil Conservation Department. Hazaribagh, India

Dearing JA, Jones RT (2003) Coupling temporal and spatial dimensions of global sediment flux through lake and marine sediment records. Global Planet Change 39(1-2):147-168

Deore SJ (2005) Prioritization of Micro-watersheds of upper bhama basin on the basis of soil erosion risk using remote sensing and GIS technology. Dissertation, Pune University, India

Donnell TKO, Baffaut C, Galat DL (2008) Predicting effects of best management practices on sediment loads to improve watershed management in the Midwest, USA. Int J River Basin Manag 6(3):243-256

Fan JR, Zhang JH, Zhong XH, Liu SZ, Tao HP (2004) Monitoring of soil erosion and assessment for contribution of sediments to rivers in a typical watershed of the upper Yangtze river basin. Land Degrad Dev 15:411-421

Furnans J, Austin B (2008) Hydrographic survey methods for determining reservoir volume. Environ Model Softw 23:139-146

Goel MK, Jain SK, Agarwal PK (2002) Assessment of sediment deposition rate in Bargi Reservoir using digital image processing. Hydrol Sci J 47(1):81-92

Haregeweyn N, Melesse B, Tsunekawa A, Tsubo M, Meshesha D, Balana BB (2012) Reservoir sedimentation and its mitigating strategies: a case study of Angereb reservoir (NW Ethiopia). J Soil Sediment 12:291-305

Heidarnejad M, Golmaee SH, Mosaedi A, Ahmadi MZ (2006) Estimation of Sediment Volume in Karaj Dam Reservoir (Iran) by Hydrometry Method and a Comparison with Hydrography Method. Lake Reserv Manag 22(3):233-239

Hunink JE, Niadas IA, Antonaropoulos P, Droogers P, Vente JD (2013) Targeting of intervention areas to reduce reservoir sedimentation in the Tana catchment (Kenya) using SWAT. Hydrol Sci J 58(3):600-614

Jothiprakash V, Garg V (2009) Reservoir sedimentation estimation using artificial neural network. J Hydrol Eng 14(9):1035-1040

Kannan N, White SM, Worrall F, Whelan MJ (2007) Sensitivity analysis and identification of the best evapotranspiration and runoff options for hydrological modeling in SWAT-2000. J Hydrol 332:456-466

Karale RL, Bali YP, Narula KK (1977) Priority watershed for soil conservation works in Matatila catchment. J Indian Soc Soil Sci 25:331-336

Mapfumo E, Chanasyk D, Willms WD (2004) Simulating daily soil water under foothill fescue grazing with the soil and water assessment tool model (Alberta, Canada). Hydrol Process 18:2787-2800

McCully P (1996) Silenced Rivers: The ecology and politics of large dams. Zed Books, London, p 350

Mishra A, Kar S (2012) Modelling hydrologic processes and NPS pollution in a small watershed in sub-humid subtropics using SWAT. J Hydrol Eng 17:445-454

Mishra A, Kar S, Singh VP (2007) Prioritizing structural management by quantifying the effect of land use and land cover on watershed runoff and sediment yield. Water Resour Manag 21:1899-1913

Moriasi DN, Arnold JG, Van Liew MW, Bingner RL, Harmel RD, Veith TL (2007) Model evaluation guidelines for systematic quantification of accuracy in watershed simulation. Trans ASABE 50(3):885-900

Morris GL, Fan J (1998) Reservoir sedimentation handbook. McGraw Hill, New York

Mueller EN, Guntner A, Francke T, Mamede G (2010) Modeling sediment export, retention and reservoir sedimentation in drylands with the WASA-SED model. Geosci Model Dev 3:275-291

Neitsch SL, Arnold JG, Kiniry JR, Williams JR (2005) SWAT theoretical documentation version 2005. Grassland, soil and water research laboratory, agricultural research service, temple

Pandey A, Chowdary VM, Mal BC (2007) Identification of critical erosion prone areas in the small agricultural watershed using USLE, GIS and remote sensing. Water Resour Manag 21:729-746

Roosmalen LV, Sonnenborg TO, Jensen KH (2009) Impact of climate and land use change on the hydrology of a large-scale agricultural catchment. Water Resour Res 45:1-18

Rose NL, Morley D, Appleby PG, Battarbee RW, Alliksaar T, Guilizzoni P, Jeppesen E, Korhola A, Punning J (2011) Sediment accumulation rates in European lakes since AD 1850: trends, reference conditions and exceedance. J Paleolimnol 45:447-468

Sardar B, Singh AK, Raghuwanshi NS, Chatterjee C (2013) Hydrological modeling to identify and manage critical erosion prone areas for improving reservoir life - a case study of Barakar river basin. J Hydrol Eng 19(1):196-204

Schiefer E, Petticrew EL, Immell R, Hassan MA, Sonderegger DL (2013) Land use and climate change impacts on lake sedimentation rates in western Canada. Anthropocene 3:61-71

Singh G, Babu R, Narain P, Bhushan LS, Abrol IP (1992) Soil erosion rate in India. J Soil Water Conserv 471:97-99

Smith C, Willians J, Nejadhashemi AP, Woznicki C, Leatherman J (2013) Cropland management versus dredging: an economic analysis of reservoir sediment management. Lake Reserv Manag 29(3):151-164

Srinivasan MS, Gerard PM, Veith TL, Gburek WJ, Steenhuis TS (2005) Watershed scale modeling of critical source areas of 
runoff generation and phosphorus transport. J Am Water Resour Assoc 41(2):361-375

Tian YC, Zhou YM, Wu BF, Zhou WF (2009) Risk assessment of water soil erosion in upper basin of Miyun Reservoir Beijing China. Environ Geol 57:937-942

Tripathi MP, Panda RK, Raghuwanshi NS (2003) Identification and prioritization of critical sub-watersheds for soil conservation management using SWAT model. Biosyst Eng 85(3):365-379

Tripathi MP, Panda RK, Raghuwanshi NS (2005) Development of effective management plan for critical sub-watersheds using SWAT model. Hydrol Process 19:809-826

Tuppad P, Kannan N, Srinivasan R, Rossi CG, Arnold JG (2010) Simulation of agricultural management alternatives for watershed protection. Water Resour Manag 24:3115-3144
Walling DE (2006) Human impact on land-ocean sediment transfer by the world's rivers. Geomorphology 79:192-216

Wu CH, Chen CN, Tsai CH, Tsai CT (2012) Estimating sediment deposition volume in a reservoir using the physiographic soil erosion-deposition model. Int J of Sediment Res 27:362-377

Xu ZX, Pang JP, Liu CM, Li JY (2009) Assessment of runoff and sediment yield in the Miyun Reservoir catchment by using SWAT model. Hydrol Process 23:3619-3630

Zhang X, Zhang M (2011) Modeling effectiveness of agricultural BMPs to reduce sediment load and organophosphate pesticides in surface runoff. Sci Total Environ 409:1949-1958

Zhang X, Wu B, Ling F, Zeng Y, Yan N, Yuan C (2010) Identification of priority areas for controlling soil erosion. Catena 83:76-86 